\title{
Workers of the hospital maintenance sector: protection, hearing symptoms and noise exposure
}

\author{
Flávia Elisa Antunes Lemes de Oliveira Ramos(1) \\ Adriana Bender Moreira de Lacerda ${ }^{(2)}$ \\ Evelyn Joice Albizu ${ }^{(3)}$
}

\begin{abstract}
(1) Universidade Federal do Paraná, Hospital de Clínicas, Curitiba, Paraná, Brasil.

(2) Universidade Tuiuti do Paraná, Curitiba, Paraná, Brasil.

(3) Fundação Jorge Duprat de Figueiredo de Segurança e Medicina do Trabalho FUNDACENTR0, Curitiba, Paraná, Brasil.

Study held at the Post-graduation Program in Communication Disorders, Universidade Tuiuti do Paraná, Curitiba, Paraná, Brasil.

Conflict of interests: Nonexistent
\end{abstract}

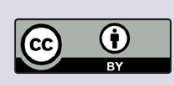

Received on: January 1, 2017

Accepted on: June 19, 2018

\section{Corresponding author:}

Flávia Elisa Antunes Lemes de Oliveira Ramos

Rua Chichorro Jr., n 410, apto 32, B airro Cabral

CEP: 80035-040 - Curitiba, Paraná, Brasil E-mail: fla-elisa@hotmail.com

\section{ABSTRACT}

Purpose: to investigate the use of hearing protection and symptoms in hospital maintenance workers and evaluate the noise level of the machines.

Methods: a cross-sectional quantitative study held with workers from a public hospital maintenance service. A questionnaire related to personal, clinical and occupational history was used. Measurement of the noise level of the machines in the sector was carried out using a sound pressure level meter.

Results: 57 male workers participated, mean age of 43.28 years, among the workers, carpentry prevailed (10.53\%), length of time at the job averaged 8.9 years and 9.3 daily work hours; $45.76 \%$ did not know what could be done to reduce maintenance noise; $59.65 \%$ wore hearing protectors at work, ear plug model (47.37\%), and $82.45 \%$ thought that the noise was reduced when they wore the hearing protector correctly. Auditory and non-auditory signs and symptoms were denied by most workers. Noise perception in the maintenance service was medium (53\%) and high (44\%), evidenced noise levels of 62.0 to $101 \mathrm{~dB}(A)$.

Conclusion: the hearing protector was worn by $59.7 \%$ of the workers, the plug model was the most used $(47.4 \%)$ and $75.8 \%$ reported that occupational noise decreased with the use of hearing protectors. Most workers use hearing protection and have no hearing symptoms. However, the presence of symptoms such as otalgia (8.8\%), otorrhea $(5.3 \%)$, dizziness $(14.0 \%)$, tinnitus $(17.5 \%)$ and difficulty in speech comprehension $(7,0 \%)$ should be pointed out. Noise assessment showed high levels from some maintenance machinery, representing a risk for hearing. The sectors of the woodwork and metalwork were the noisiest.

Keywords: Noise Effects; Workers' Health; Hearing; Occupational Exposure 


\section{INTRODUCTION}

Hospital maintenance features as a service provider, responsible to supply service requests from the hospital complex in an efficient, effective and fast way, such as: fixing, repairing, restoration, conservation, reform and construction. Facilities in those settings must be kept in good conditions of conservation, safety, organization, comfort and cleanliness; water and electricity must continue being supplied in case of interruption. Thus, hospital maintenance makes sure that machinery and facilities are working properly, providing comfort and safety conditions for the development of several activities in the institution. In addition, preventive and corrective maintenance actions of the building facilities must be reassured in order to contribute to the ongoing enhancement of health care services ${ }^{1}$.

However, to most hospitals, maintenance services are not viewed as essentially important ${ }^{2}$. In hospital settings, attention is usually focused on the health care professionals, aiming at prevention from damages or occupational accidents. The other professionals, although their exposed to hazards, they do not have the same attention, which may cause implications for workers' health, particularly the ones from hospital maintenance.

Work conditions at the hospital maintenance service are unhealthy, as there are environmental hazards to workers' health, mainly the physical risk, once noise is produced by the machines they use ${ }^{3}$.

Noise is an undesirable sound, and it is the commonest physical agent among the occupational hazards at workplace, which may cause deleterious effects to health and hearing ${ }^{4}$. That risk is present at several workplaces, among them, in hospital maintenance, where services, such as woodwork, metalwork, masonry work, boiler, electrical fixtures, hydraulics, gardening are concentrated, among others ${ }^{5}$. Nevertheless, studies related to workers' hearing health are still incipient in this sector, therefore, research in this area is required.

Noise may harm hearing and cause difficulty in speech understanding, tinnitus, cephalea, aural fullness, dizziness, stress, nervousness, irritability, gastric disorders, circulatory dysfunctions of eyes, attention and memory, sleep and mood, among others ${ }^{6,7}$.

Auditory and non-auditory effects will depend on noise frequency, intensity, duration and rhythm, as well as the time length of exposure to it and individual susceptibility ${ }^{4,8}$.
Noise-Induced Hearing Loss (NIHL) features as a neurosensory hearing loss, notched audiometric configuration, usually symmetric, bilateral, irreversible and progressive. NIHL is considered one of the commonest occupational diseases in the industrial activity, and is totally preventable ${ }^{4,8}$.

According to a study ${ }^{9}$, statistics on noise exposure is not available for most industrialized and non-industrialized countries. However, high levels of occupational noise exposure were reported in 17 studies held in 12 countries of South America, Africa and Asia. Such high levels of noise were verified at workplaces, and in many of those studies, hearing loss was reported in the exposed workers.

Millions of workers in Europe have been exposed to occupational noise and subject to hearing damage. About $7 \%$ of them suffer from occupational hearing disorders, and NIHL is allegedly one of the most prevalent occupational diseases in the European Union $^{10}$.

An American study suggests that hearing loss is the third commonest chronic physical condition in the United States, more prevalent than diabetes or cancer, and occupational hearing loss, mostly caused by exposure to high noise levels is the commonest occupational disease in the United States ${ }^{11}$.

In Brazil, there are no precise data on noise exposure among the economically active population, which hinders an estimation about the number of exposed workers, as well as the identification of the most hazardous lines of business, highly useful information for NIHL monitoring and prevention ${ }^{12,13}$.

Considered a public health problem, NIHL is preventable by means of protection, prevention and health promotion actions, putting forth joint measures and the effective participation of workers in prevention programs, assessing social determinants and organizational factors ${ }^{12,13}$.

Therefore, research on the hearing health of noiseexposed workers is valuable, including workers from the hospital maintenance sector, whose studies are scarce or non-existent. Thus, the current study aims at investigating the use of protection as well as the hearing symptoms of workers from the hospital maintenance sector, in addition to the assessment of the machinery noise levels.

\section{METHODS}

This research was approved by the Research Ethics Board of the Hospital de Clínicas, Federal University 
of Paraná, register number 32003014.9.3001.0096. Workers from the hospital maintenance sector were invited to participate in the study and informed about its objective, and all of them signed the Free Informed Consent Form.

It is a cross-sectional quantitative study, developed at a large Federal Public Hospital Maintenance Service from June 2014 to April 2015, having hospital maintenance workers as participants in the research.

The inclusion criterium was to be a hospital maintenance worker in the areas of metalwork, mechanics, boiler, woodwork, medical gases, masonry work, electrical, hydraulic work and gardening, exposed or not to noise levels greater than $80 \mathrm{~dB}(\mathrm{~A})$ or other ototoxic agents.

Initially, an adapted questionnaire was applied ${ }^{14}$ (Appendix 1), comprising open and closed questions, including personal data as well as workers' clinical and occupational history.

In the current study, the questions analyzed related to: sociodemographic data (gender, age and schooling); current position (1.1); employment relationship (1.2); length of time at the job (1.5); daily work hours (1.6); noise perception at the maintenance sector (1.7); knowledge on measures for noise reduction (1.10); use and type of hearing protector (1.11); guidance on hearing protection (1.12); perception on the use of hearing protection (1.13); exposure to chemicals at workplace (1.14); former occupational noise exposure (1.15); audiometric exam (2.1); history of morbidity (3); hearing symptoms (5.1 to 5.5); difficulty in speech understanding (5.10).

Subsequently, the assessment of environmental noise level was carried out by a certified professional, using a Bruel \& Kjaer 2238 sound pressure meter, duly calibrated. The technical assessment procedures, recommended by the Occupational Hygiene Regulations 01 from Jorge Duprat Figueiredo Foundation for Occupational Safety and Medicine (FUNDACENTRO), were complied ${ }^{15}$. Measurement was performed in workers' hearing area (delimited by a radius of $150 \mathrm{~mm} \pm 50 \mathrm{~mm}$, measured from the entrance of the ear canal).

The reference criterium adopted was $85 \mathrm{~dB}(\mathrm{~A})$ for an 08-hour working day, dose duplication increase (q) = 5 , integration threshold of $80 \mathrm{~dB}(\mathrm{~A})$, Leq readings and minimum and maximum levels. Three-minute evaluations were performed for each equipment at work. All machines were turned on, one at a time, for the assessment (except for the router and dust collector which were jointly evaluated). Evaluations were carried out during regular work hours and tasks. Despite the complex operational dynamic activity, it was opted for checking sound pressure level of each equipment as if it operated alone in the environment.

Statistical analysis was carried out by means of Descriptive Statistical Methods (frequency tables, mean/median, minimum, maximum, standard deviation). Sphinx for Windows software was used for the analyses.

\section{RESULTS}

Hospital maintenance team comprised 86 workers during the study. Twenty-nine (29 - 33.7\%) workers were excluded from the study, as 20 of them did not work in the sector anymore, 2 were on sick leave, one was on vacation, and 6 refused to participate in the study.

Therefore, 57 workers (66.3\%) participated in the study, all males, ages ranging from 21 to 75 years (mean age of 43.3 years and standard deviation of 13.3 years). As for schooling, $31.6 \%$ had incomplete middle school (9 years), 29.8\% complete high school, $21.1 \%$ complete middle school, $14 \%$ incomplete high school, and $3.5 \%$ complete Higher Education.

The maintenance service had three different employment relationships: the permanent employees (under an exclusive legal system) (5.3\%); the ones hired by the foundation (17.5\%) and the outsourced ones $(77.2 \%)$ both under the Consolidation of Labor Laws (CLT). It should be pointed out that labor relations did not influence or had no relation to the sectors, job positions or risk agents in the maintenance sector, including the exposure to different noise levels.

Mean length of time at the job in the maintenance service was 8.9 years and mean hours of working day was 9.3 hours. The prevalent jobs were carpenter $(10.5 \%)$, boiler operator, bricklayer and electrician with $8.8 \%$ for each job.

Workers reported exposure to chemicals at workplace (64.9\%); noise exposure in the former job (66.7\%); and non-occupational noise exposure (40.4\%). (Table 1)

All of them underwent audiometric exam at work, and $31.6 \%$ mentioned history of morbidity. As for hearing complaints, $8.8 \%$ reported otalgia, $5.3 \%$ reported otorrhea, $14.0 \%$ complained about dizziness, and $17.5 \%$ reported tinnitus. Difficulty in speech understanding was mentioned by $7.0 \%$ of the participants (Table 1). 
Table 1. Sample distribution according to maintenance workers' clinical and occupational history $(n=57)$

\begin{tabular}{|c|c|c|}
\hline Variables & $\begin{array}{c}\text { Absolute Frequency } \\
\text { N }\end{array}$ & $\begin{array}{c}\text { Relative Frequency } \\
\% \\
\end{array}$ \\
\hline Chemical exposure at workplace & 37 & 64.9 \\
\hline Exposure to high noise levels at former job & 38 & 66.7 \\
\hline Non-occupational noise exposure & 23 & 40.4 \\
\hline Audiometric testing at the workplace & 57 & 100 \\
\hline History of morbidities & 18 & 31.6 \\
\hline Otalgia complaint & 5 & 8.8 \\
\hline Otorrhea complaint & 3 & 5.3 \\
\hline Dizziness complaint & 8 & 14.0 \\
\hline Tinnitus complaint & 10 & 17.5 \\
\hline Report of difficulty in speech understanding & 4 & 7.0 \\
\hline
\end{tabular}

When workers' opinions about what could be done to reduce noise in the maintenance were categorized, $45.8 \%$ did not know the solution, $25.4 \%$ mentioned joint measures for protection, $15.3 \%$ mentioned individual protection, and $10.2 \%$ mentioned administrative measures (Figure 1).

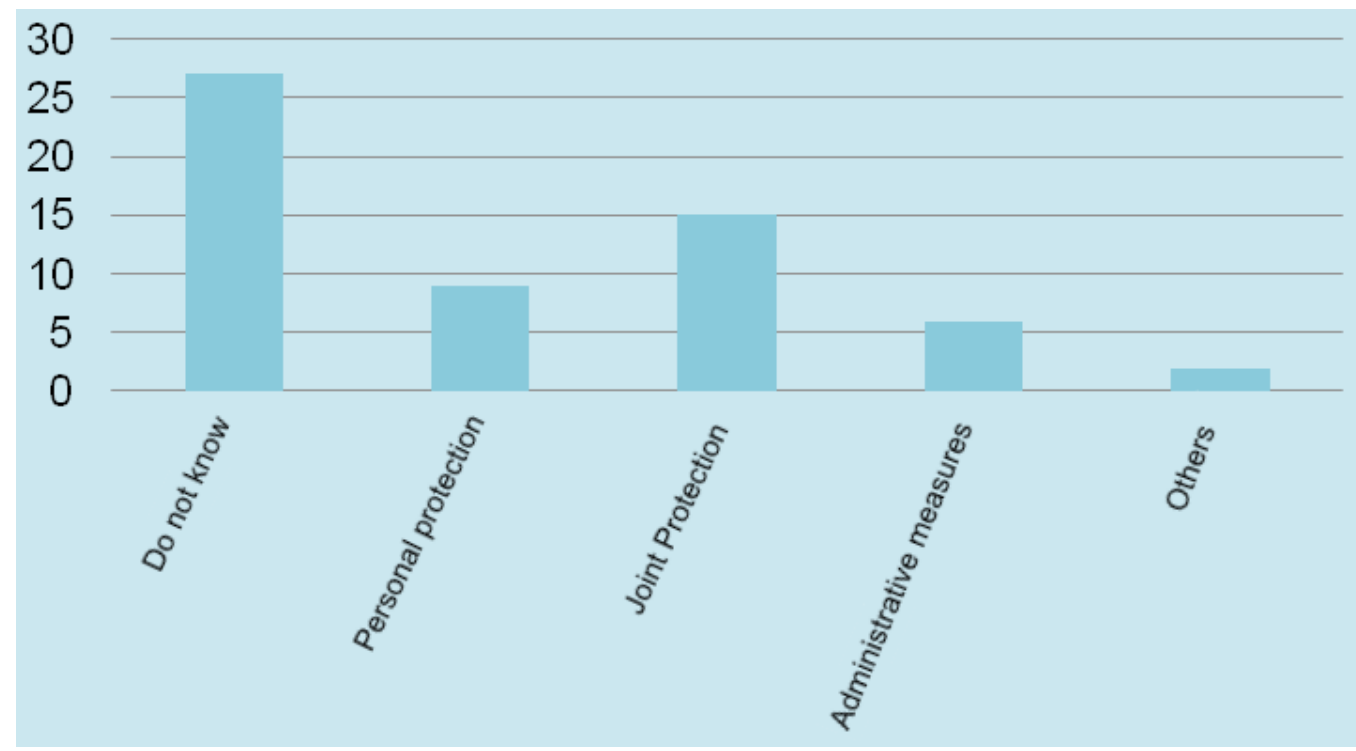

Figure 1. Workers' knowledge on measures to reduce noise in the maintenance sector

Regarding the guidance on hearing protection, 98.3\% answered affirmatively. Hearing protection was used by $59.7 \%$ of the workers, ear-plug model was the best used $(47.4 \%)$, hearing protectors were sometimes worn by $24.6 \%$, and $12.3 \%$ did not wear any hearing protectors. In relation to the considerations on the use of hearing protection, $75.8 \%$ claimed that the use of hearing protectors reduced occupational noise, $8.1 \%$ answered that it is hard to talk with them (Table 2). 
Table 2. Workers' sample distribution on guidance, use, type and their considerations on the use of hearing protection $(n=57)$

\begin{tabular}{lcc}
\hline Variables & $\begin{array}{c}\text { Absolute Frequency } \\
\mathbf{n}\end{array}$ & $\begin{array}{c}\text { Relative Frequency } \\
\%\end{array}$ \\
\hline GUIDANCE & 56 & 98.3 \\
Yes & 1 & 1.8 \\
No & 34 & 59.7 \\
\hline USE & 7 & 12.3 \\
Yes & 16 & 28.1 \\
No & & \\
Sometimes & 7 & 12.3 \\
\hline TYPE OF PROTECTORS & 9 & 15.8 \\
Did not wear & 27 & 47.4 \\
Ear muffs & 14 & 24.6 \\
Ear plugs & & \\
Ear muffs and plugs & 3 & 4.8 \\
\hline CONSIDERATIONS ON THEIR USE & 47 & 75.8 \\
Do not wear them & 5 & 8.1 \\
Occupational noise is reduced & 3 & 4.8 \\
They disturb talking & 3 & 4.8 \\
Protectors bother me & 1 & 1.6 \\
I wear them because it's mandatory & & \\
Makes no difference to wear them & & \\
\hline
\end{tabular}

Figure 2 shows workers' answers on noise levels in the hospital maintenance sector, with $52 \%$ of the workers considering them medium, $44 \%$ considered them high, and $4 \%$ considered them low.

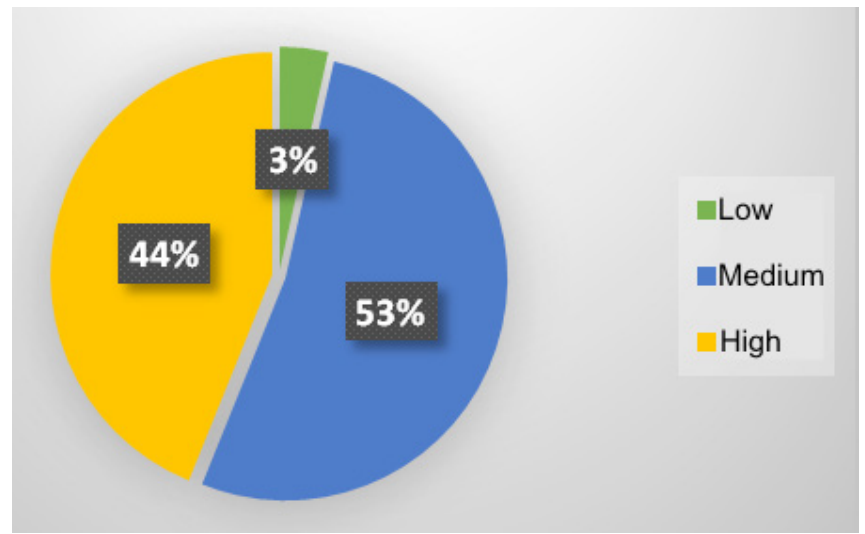

Figure 2. Distribution of workers' answers on noise levels in the maintenance sector
According to the measurement results of the noise levels in the hospital maintenance machinery, handsaw for woodwork was the noisiest machine, featuring 101.0 $\mathrm{dB}(\mathrm{A})$ as the equivalent level of noise, followed by the marble saw cutting metal, which featured $99.9 \mathrm{~dB}(\mathrm{~A})$ as the equivalent level of noise, and the same machine cutting tiles featured $98.2 \mathrm{~dB}(\mathrm{~A})$, the multi-cutter saw for iron reached $98.7 \mathrm{~dB}(\mathrm{~A})$, and the sander reached 98.2 $\mathrm{dB}(\mathrm{A})$ (Table 3). 
Table 3. Machine distribution in the hospital maintenance sector, according to the result of noise level assessment

\begin{tabular}{|c|c|c|c|c|}
\hline Machine & Sector & $\begin{array}{l}\text { Leq }^{*} \\
d B(A)^{* *}\end{array}$ & $\begin{array}{l}\operatorname{Max} \\
\mathrm{dB}(\mathrm{A})\end{array}$ & $\begin{array}{c}\text { Min } \\
\mathrm{dB}(\mathrm{A})\end{array}$ \\
\hline Handsaw & Marcenaria & 101.0 & 108.4 & 65.5 \\
\hline \multicolumn{5}{|l|}{ Marble Saw: } \\
\hline Cutting metal & & 99.9 & 109.3 & 77.0 \\
\hline Cutting tiles & & 98.2 & 109.3 & 70.8 \\
\hline Iron multi-cutter saw & Metalwork & 98.7 & 103.6 & 71.3 \\
\hline Sander & Metalwork & 98.2 & 105.5 & 86.7 \\
\hline Aluminum multi-cutter saw & Metalwork & 97.7 & 107.7 & 60.6 \\
\hline Grinding wheel & Metalwork & 96.9 & 103.1 & 88.7 \\
\hline Coping saw & Woodwork & 95.0 & 106.7 & 82.2 \\
\hline Hand Electric Planer & Woodwork & 95.0 & 103.3 & 88.1 \\
\hline Brush cutter & Gardening & 94.9 & 102.4 & 78.2 \\
\hline Power Hand Drill & Woodwork & 94.4 & 97.9 & 87.1 \\
\hline Compressed air nozzle & Woodwork & 93.8 & 100.0 & 90.7 \\
\hline Router + Exhaust (together) & Woodwork & 93.1 & 99.8 & 78.7 \\
\hline \multicolumn{5}{|l|}{ Circular saw B: } \\
\hline \multirow{2}{*}{$\begin{array}{l}\text { Cutting solid wood } \\
\text { Cutting leaked wood }\end{array}$} & \multirow{2}{*}{ Woodwork } & 91.7 & 106.8 & 79.4 \\
\hline & & 89.5 & 99.6 & 83.4 \\
\hline \multirow{2}{*}{ Woodwork grinding wheel (sharpening drill) } & \multirow{2}{*}{ Woodwork } & 80.5 & 90.0 & 73.7 \\
\hline & & 87.5 & 93.4 & 77.4 \\
\hline \multirow{2}{*}{ Circular saw A (cutting wood) } & \multirow{2}{*}{ Woodwork } & 83.3 & 94.4 & 76.2 \\
\hline & & 87.1 & 94.5 & 82.6 \\
\hline Boiler & Boiler & 84.6 & 90.7 & 80.2 \\
\hline \multirow{2}{*}{ Woodwork sander (sanding wood) } & \multirow{2}{*}{ Woodwork } & 83.5 & 94.5 & 79.0 \\
\hline & & 84.1 & 94.5 & 79.0 \\
\hline Bench Drill & Woodwork & 83.1 & 88.8 & 81.0 \\
\hline Dust collector & Woodwork & 81.3 & 92.6 & 81.0 \\
\hline Paint spray gun & Painting & 67.8 & $\begin{array}{l}92.0 \text { (background } \\
\text { noise - disregard) }\end{array}$ & 72.8 \\
\hline Exhaust (on - alone) & Woodwork & 62.0 & 87.2 & 67.2 \\
\hline Welding (red) & Metalwork & - & 84.5 & 82.0 \\
\hline
\end{tabular}

NOTA: Leq* - equivalent continuous sound level; Max - Maximum; Min - Minimum

$\mathrm{dB}(\mathrm{A})^{\star *}$ - sound pressure level in decibels, A-weighting filter, which is similar to the response of the human ear.

\section{DISCUSSION}

The current study aimed to investigate the use of hearing protection and symptoms in workers from the hospital maintenance sector, in addition to the assessment of noise levels of the machinery.

Due to the scarcity of studies on workers' hearing health in the hospital maintenance sector, also called building maintenance, studies related to similar services performed by the workers from hospital maintenance were searched, such as repairs, restorations, conservation, reforms and construction, including the jobs performed by electricians, bricklayers, carpenters, among other jobs required in the hospital maintenance service.
Building maintenance service rendered in Health Care Facilities is indispensable to ensure users' safety within health care facilities ${ }^{1}$. If that is supposed to occur, it is understood that health promotion and quality of life enhancement of workers in those services are paramount, by means of educational interventions which contribute to preventive actions at their workplace, prevailing the occupations of carpenters $(10.5 \%)$, electricians, boiler operators and bricklayers (8.8\% each).

Other studies with maintenance workers describe similar jobs ${ }^{2,3}$. Study within a Federal Educational Institution assessed the risks which maintenance workers are exposed to, and concluded that the main 
maintenance jobs were plumbers, welders, electricians, bricklayers, gardeners and upholsterers, and their major risks were noise, outdated equipment, work at heights and exposure to chemicals ${ }^{3}$.

Another study evidenced the existence of maintenance services in a private, medium-sized, high complexity hospital in the interior of São Paulo State, and concluded that, within hospital settings, maintenance contributes to improve the environment, and may influence health care safety, health care team's productivity, hospital infection indicators, decrease of work accidents, in addition to potentialize humanized care $^{2}$.

Thus, it is essential to ensure the satisfactory functioning of that sector, by valuing its workers, detecting hazards they are exposed to, adopting preventive measures, aiming at health promotion and quality of life.

Other studies still report that some workers are vulnerable to noise, such as welders, carpenters, electricians, mechanics and bricklayers, and may be included among the professionals at greater risk for $\mathrm{NIHL}$, with age, time length of exposure to occupational noise as contributing factors to hearing disorders ${ }^{16-18}$.

In this study, time length of occupational noise exposure averaged 8.9 years for 9.3 hours of working day. Another study evidences that the risk for developing occupational $\mathrm{NIHL}$ increases according to the time length of exposure in years ${ }^{19}$.

Maintenance workers' occupational history unveils former noise exposure (66.7\%). In their current job, in addition to noise exposure, they were also exposed to chemicals $(64.9 \%)$. Studies show that exposure to chemicals (solvent, among them) is potentially ototoxic, and added to noise, may contribute to the development or aggravation of hearing loss ${ }^{20-22}$.

As for their medical records, results report former morbidities (31.6\%), in addition to hearing complaints, among them, dizziness (14.0\%) and tinnitus (17.5\%) stood out. It should be pointed that non-auditory symptoms were not broadly analyzed in the current study, however, they should be investigated in the anamnesis ${ }^{4,23,24}$.

In a study to verify the occurrence of auditory and non-auditory symptoms in workers from a glass processing plant, exposed to noise levels greater than $85.0 \mathrm{dBA}$, in Salvador (Bahia State, Brazil) in 2010, it was evidenced that the most reported hearing symptoms were tinnitus and loudness discomfort, while the most reported non-auditory symptoms were anxiety, cephalea, gastric disorders and insomnia ${ }^{24}$. Symptoms, such as loudness discomfort (30.1\%); tinnitus (24\%), aural fullness (22.9\%); hearing loss (21.6\%); and otalgia (13.2\%) were also identified after exposure to high noise levels by workers from a tile manufacturing plant in João Pessoa (Paraíba State, Brazil) ${ }^{25}$.

Being questioned about audiometric assessment, all of the hospital maintenance workers confirmed that they undergo audiometric testing in their current job, evidencing the compliance to the current regulations in the country. Audiometric testing is recommended to assess and follow up hearing of workers exposed to high sound pressure levels, according to Ordinance 19, Labor Ministry ${ }^{26}$.

In order to verify workers' knowledge on preventive measures, it was asked them what could be done to reduce noise within the hospital maintenance sector. Results showed that $45.8 \%$ of the workers did not know about the subject. The other workers suggested joint preventive measures for noise control (25.4\%). That evidences workers' knowledge on the need to prioritize the adoption of joint measures for noise control.

It is known that joint measures to reduce and control noise exposure to machinery and equipment are priority. However, it is still observed noisy machines and equipment, without proper maintenance, nor the adoption of preventive measures ${ }^{27}$.

Still about that issue, personal protection was mentioned by $15.3 \%$ of the workers, and administrative measures by $10.2 \%$ of them. There has been common agreement that occupational hearing disorders can be prevented by means of a control hierarchy, putting the use of engineering control over administrative control and personal protection equipment ${ }^{8}$. However, the use of personal protection equipment (PPE) has been the only preventive measure adopted by workers in many jobs ${ }^{12,28}$, including in the current study.

As for the use of PPE, it was analyzed the guidance provided on the use of hearing protection, and most of them $(98.3 \%)$ reported that they had been guided on its use, with $59.7 \%$ reporting its use. Ear-plug model was worn by $47.4 \%$ of workers. In this aspect, training programs strengthened the importance of hearing health prevention and promotion, and may positively influence the use of hearing protectors in noisy workplaces ${ }^{29}$.

In a study carried out to investigate $\mathrm{NIHL}$ in 60 woodworkers from the construction field, $63 \%$ of those workers reported to wear hearing protectors regularly, mostly ear-plug model ${ }^{16}$. Another study with 15 workers 
from a food company in Curitiba, Paraná State - Brazil, where the efficiency of hearing health workshops as a proposal of educational intervention for noise-exposed workers was analyzed, it was evidenced that $73.3 \%$ of the workers also wore that type of hearing protector ${ }^{30}$, similarly to the current study. Nevertheless, it is essential knowledge on noise and its health outcomes for workers to get involved in the adoption of preventive measures.

Regarding the use of hearing protection, $75.8 \%$ of the workers answered that occupational noise was reduced by using protection. A similar result was found by the authors when they evaluated and compared the perception of 440 workers from a logging company in municipalities from the interior of Paraná State, Brazil. They concluded that the most relevant aspects considered for the use of the equipment were noise reduction by the protector and verbal communication ${ }^{31}$.

As for the noise levels of the machines in the hospital maintenance, $52 \%$ of the workers considered them medium level, $44 \%$ considered them high, and $4 \%$ of the workers considered them low. Noise produced by machines in a tool manufacturing plant in Espírito Santo State, Brazil, was also considered excessively high by $76 \%$ of the workers ${ }^{32}$.

The incorporation of workers' risk perception and the ways to include workers' knowledge, as they experience risk situations and events, is an important step for risk identification and transformation ${ }^{12}$. Study shows that workers questioned about their knowledge on noise risks for health, $76 \%$ reported that they knew about those risks, not only for general health, but also for hearing health ${ }^{25}$.

The assessment results for the noise levels of the machines from the hospital maintenance sector corroborate workers' reports that noise levels in the maintenance is high, and the studied population is exposed to the risk of developing hearing loss, evidencing noise levels ranging from $67.2 \mathrm{~dB}(\mathrm{~A})$ to $109.3 \mathrm{~dB}(\mathrm{~A})$. It should be pointed out that the sound pressure level of most equipment was measured as if they operated individually in the environment, although maintenance has a complex and variable dynamic operational activity, depending on the job demand. With several machines working at the same time, the final sound pressure level could be higher than the one evaluated in this study, aggravating the risk for the exposed workers.

It was verified that 15 out of the 22 machines analyzed at the equivalent continuous sound level (Leq) featured sound pressure level greater than $85 \mathrm{~dB}(\mathrm{~A})$, only 2 machines had levels lower than $85 \mathrm{~dB}(\mathrm{~A})$, which may hinder general and hearing health of the exposed workers, unless preventive measures are not effectively adopted. During the measurement of noise levels in furniture manufacturing plants in Minas Gerais State, Brazil, it was also verified that most analyzed machines evidenced equivalent continuous sound level greater than the tolerance threshold of $85 \mathrm{~dB}(\mathrm{~A})^{33}$.

Noise assessment of the machines shows that the handheld circular saw, the marble saw, multi-cutter saw, sander, grinding wheel, coping saw and electric planer are the noisiest. Assessment results corroborate a study which suggests that planers and electric saws are among industrial machinery able to produce noise of approximately $100 \mathrm{~dB}(\mathrm{~A})$ and cause $\mathrm{NIHL}^{34}$.

A literature review, which assessed noise in hospital settings, pointed that $38.1 \%$ of the analyzed studies recommended the implementation of educational interventions to reduce environmental noise; $19.0 \%$ recommended noise surveillance, in addition to sound adaptation of equipment and architectural adaptations with managers' involvement ${ }^{35}$.

Based on the results of the current study, it is recommended the implementation of preventive measures to eliminate or reduce hearing hazards among hospital maintenance workers. It can be understood that once the risks of the occupational noise are known, as well as its impact on general and hearing health of exposed workers, it is advisable to adopt individual and joint preventive measures which favor the reduction or elimination of the risk at workplaces; to make employers aware of the importance of a Prevention Program on Hearing Loss; and to guide workers, aiming at fostering those individuals' quality of life $\mathrm{e}^{24}$.

As a limitation in this study, noise assessment of the machines did not consider the regular work in the sector, where all machines could work at the same time, and also it did not have access to the quantitative analysis of other noise-related risk factors. The questionnaire used is long, which contributed to the refusal in participating of some workers. Further studies should consider those factors so that noise and its auditory and non-auditory effects be better profiled.

\section{CONCLUSION}

The results obtained enabled to investigate the use of hearing protection and symptoms in workers from the hospital maintenance sector, in addition to the noise level assessment of the machines in this sector, scarcely found in the literature. 
Hearing protector was worn by $59.7 \%$ of the workers, ear-plug model was the most worn (47.4\%), and $75.8 \%$ of them reported that occupation noise was reduced with the use of hearing protectors.

Most workers did not report hearing disorders, although the presence of symptoms, such as otalgia $(8.8 \%)$, otorrhea $(5.3 \%)$, dizziness $(14.0 \%)$, tinnitus $(17.5 \%)$ and difficulty in speech understanding (7.0\%) should be pointed out. Noise levels were considered medium or high by most workers from the sector.

Noise assessment corroborates workers' report on the occupational noise levels and evidenced high levels from the machinery in the maintenance, posing risk to hearing. Woodwork and metalwork sectors were the noisiest.

\section{REFERENCES}

1. Amorim GM, Quintão ECV, Martelli Júnior $\mathrm{H}$, Bonan PRF. Prestação de serviços de manutenção predial em estabelecimentos assistenciais de saúde. Ciência \& Saúde Coletiva. 2013;18(1):145-58.

2. Françolin L, Camargo RA, Santos CA, Di Lello CP, Rossatto AR. Gerenciamento de risco hospitalar: um olhar para as ordens de serviços do setor de manutenção. Rev Adm Saúde. 2011;13(50):23-30.

3. Veronezi CTP, Catai RE. Análise preliminar de risco na manutenção predial de uma instituição federal de ensino superior. R. Eng. Constr. Civ. 2014;1(1):48-62.

4. Brasil. Secretaria de Atenção à Saúde. Departamento de Ações Programáticas Estratégicas. Perda auditiva induzida por ruído (PAIR). Brasília: Editora do Ministério da Saúde, 2006.

5. Lizuka LY, Gil D. Audiological evaluation in employees exposed to noise in a public hospital. Rev. CEFAC. 2014;16(3):715-22.

6. Kasper KCF, Gómez MVSG, Zaher VL. The noise as a stress factor in the life of blacksmith and carpenter workers. Intern Arch of Otorhinolatyngology. 2005;9(1):302-12.

7. Costa EB, Lopes GR, Roberte R, Santos TMM. Prevalência das doenças auditivas não ocupacionais que acometem trabalhadores em processo pré-admissional. Distúrb. Comum. 2012;24(2):149-57.

8. Kirchner B, Evenson E, Dobie RA, Rabinowitz P, Crawford J, Kopke R et al. Occupational noise-induced hearing loss. J Occupational \& Environmental Medicine. 2012;54(1):106-8.
9. Nelson DI, Nelson RY, Concha-Barrientos $M$, Fingerhut $M$. The global burden ofoccupational noise-induced hearing loss. The Am $\mathrm{J}$ of Industrial Med. 2005;48(6):446-56.

10. European Agency for Safety and Health at Work - EU-OSHA. Noise. 2013. Disponível em: < http:// oshwiki.eu/wiki/Noise>. Acesso em: 03 de dez. 2015.

11. Masterson EA, Bushnell PT, Themann CL, Morata TC. Hearing impairment among noise-exposed workers - United States, 2003-2012. MMWR Morb Mortal Wkly Rep. 2016;65(15):389-94. DOI: http:// dx.doi.org/10.15585/mmwr.mm6515a213.

12. Meira TC, Ferrite S, Cavalcante F, Corrêa JM. Exposição ao ruído ocupacional: reflexões a partir do campo da Saúde do Trabalhador. Rev. InterfacEHS. 2012;7(3):26-45.

13. Cavalcante F, Ferrite S, Meira TC. Exposure to noise in the manufacturing industry in Brazil. Rev. CEFAC. 2013;15(5):1364-70.

14. Ibañez RN, Schneider LO, Seligman J. Anamnese dos trabalhadores expostos ao ruído. In: Nudelman AA (org). PAIR: perda auditiva induzida pelo ruído. Rio de Janeiro, Revinter, volume II, 2001. p.45-50.

15. Fundação Jorge Duprat Figueiredo de Segurança e Medicina do Trabalho. - FUNDACENTRO. NHO 01: Norma de higiene ocupacional - procedimento técnico. S. Paulo: FUNDACENTRO, 2001.

16. Farias VHV, Buriti AKL, Rosa MRD. Occurrence of noise induced hearing loss in carpenters. Rev. CEFAC. 2012;14(3):413-22.

17. Silva JLL, Costa FS, Souza RF, Sousa JL, Oliveira RS. O ruído causando danos e estresse: possibilidade de atuação para a enfermagem do trabalho. Avances en Enfermería. 2014;32(1):124-38.

18. Prezado ACO, Peck GMF, Souza MOPM. Prevalência de perda auditiva induzida pelo ruído nas audiometrias realizadas em trabalhadores de uma indústria de cerâmica do sul catarinense entre o período de julho de 2009 a setembro de 2010. Arq Catarinense de Medicina. 2011;40(4):36-41.

19. Oliva FC, Morata TC, Lacerda ABM, Steinmetz L, Bramatti L, Vivan AG. Mudança significativa do limiar auditivo em trabalhadores expostos a diferentes níveis de ruído. Rev Soc Bras Fonoaudiol. 2011;16(3):260-5.

20. Botelho CT, Paz APM, Gonçalves AM, Frota S. Comparative study of audiometrics tests on metallurgical workers exposed to noise only as well as noise associated to the handling of 
chemical products. Rev. Bras. Otorrinolaringol. 2009;75(1):51-7.

21. Lobato DCB, Lacerda ABM. Efeitos auditivos dos solventes: revisão de literatura. Tuiuti: Ciência e Cultura. 2013;47:67-90.

22. Morata TC, Lacerda ABM. Saúde auditiva. In: Zeigelboim BS, Zurkiewicz AL (org). Multidisciplinaridade na otoneurologia. São Paulo: Roca, 2013. p.386-99.

23. Alves AS, Fiorini AC. A autopercepção do handicap auditivo em trabalhadores de uma indústria têxtil. Distúrb. Comum. 2012;24(3):337-49.

24. Nunes CP, Abreu TRM, Oliveira VC, Abreu RM. Sintomas auditivos e não auditivos em trabalhadores expostos ao ruído. Rev Baiana de Saúde Pública. 2011;35(3):548-55.

25. Andrade WTL, Lima MAR, Soares JFR. Hearing complaints of workers in a pottery industry of the city of João Pessoa/PB. Rev. CEFAC. 2015;17(6):1874-8.

26. Brasil. Ministério do Trabalho - MT. Portaria n.o 19, de 09 de abril de 1998. - NR 7- Alterar o Quadro II - da Portaria no 24, de 29 de dezembro de 1994. Brasília: Ministério do Trabalho, 1998.

27. Lacerda ABM, Quintiliano J, Lobato D, Gonçalves $C$, Marques J. Hearing profile of brazilian forestry workers noise exposure. Int Arch Otorhinolaryngology. 2015;19(1):22-9.

28. 28 Costa JB, Rosa SAB, Borges LL, Camarano MRH. Caracterização do perfil audiológico em trabalhadores expostos a ruídos ocupacionais. EVS - Estudos Vida e Saúde. 2015;42(3):273-87.

29. Ribeiro GM, Figueiredo MFS, Rossi-Barbosa LAR. The importance of auditory health training: an integrative review. Rev. CEFAC. 2014;16(4):1318-25.

30. Moreira AC, Goncalves CGO. The workshops effectiveness educational as actions undertaken with hearing health care workers exposed to noise. Rev. CEFAC. 2014;16(3):723-31.

31. Gonçalves CGO, Lüders D, Guirado DS, Albizu EJ, Marques JM. Perception of hearing protectors by workers that participate in hearing preservation programs: a preliminary study. CoDAS. 2015;7(4):309-18.

32. Guimarães PP, Fiedler NC, Lima JSS, Leite AMP, Pelissari AL. Fatores humanos e condições de trabalho das atividades em uma fábrica de ferramentas. Nativa. Sinop. 2013;1(1):49-55.
33. Filipe AP, Silva JRM, Trugilho PF, Fiedler NC, Rabelo GF, Botrel DA. Avaliação de ruído em fábricas de móveis. CERNE. 2014;20(4):551-6.

34. Oliveira Júnior E, Almeida FSS, Morrone LC. Avaliação de riscos de uma empresa de embalagens de madeira. Rev Laborativa. [online] 2014 [cited 2016 jan 20];3(2):41-55. Available from: http://ojs.unesp.br/index.php/rlaborativa.

35. Filus WA, Pivatto LF, Fontoura FP, Koga MRV, Albizu EJ, Soares VMN et al. Noise and its impact on brazilian hospitals: a literature review. Rev. CEFAC. 2014;16(1):307-17. 


\section{APPENDIX 1 - Questionnaire}

Name:

Date:___ _ _ Age:___ Gender: Male ( ) Female ( )

Schooling: Middle School (9 years) ( ) High School ()

Complete ( ) Incomplete ( )

Complete Higher Education ( ) Incomplete Higher Education ( )

\section{DATA}

1.1 Current Job:

1.2 Category: Funpar ( ) Dean's office ( ) Outsourced ( )

1.3 Work area in the maintenance sector:

( ) metalwork and mechanics ( ) boiler ( ) transport

( ) clinical engineering ( ) gardening

( ) building and reform design and supervision ( ) medical gases

( ) masonry work, electrical fixtures and hydraulics ( ) administration of the unit

( ) engineering and hospital maintenance ( ) woodwork

1.4 Length of time in the job at the hospital:

1.5 Length of time in the job in the maintenance sector:

1.6 Hours of working day:

1.7 Impressions on the maintenance noise levels: Low ( ) Medium ( ) High ( )

1.8 What maintenance machine is the noisiest?

1.9 Did you get any guidance about the noise effects on hearing at your workplace?

Yes ( ) No ( ) If so, by whom:

1.10 In your opinion, what could be done to reduce noise in the maintenance sector?

1.11 Use of ear protector: Yes ( ) No ( ) Sometimes ( )

If so, what type: Ear muffs and plugs ( ) Ear muffs ( ) Ear plugs ( )

1.12 Have you ever got any guidance on the use of ear protectors?

Yes ( ) No ( )

By whom:

1.13 By wearing ear protectors, you can notice that:

Noise is reduced at workplace ( ) It is bad to talk ( )

The ear protectors disturb ( ) Makes no difference to wear them ( )

I cannot wear ear protectors ( ) I only wear them because they are mandatory ( )

1.14 At workplace, do you have any contact with chemicals? Yes ( ) No ( )

Which ones :

1.15 Have you ever worked in other jobs with high sound levels?

Yes ( ) No ()

Which one:

1.16 Former job: Line of business:

Function: Length of time in the job:

Noise exposure at the former job: Yes ( ) No ( ) sometimes ( )

Use of ear protectors in the former job: Yes ( ) No ( ) sometimes ( )

If so, what type: Ear muffs and plugs ( ) Ear muffs ( ) Ear plugs ( )

1.17 Are you noise-exposed out of the hospital settings? Yes ( ) No ( )

Which ones: Shows ( ) Frequent parties ( ) Ear phones ( ) Religious services ( )

Others ( ) Which ones? Amount of daily hours:

\section{FORMER AUDIOMETRIC TESTING}

2.1 Did you undergo any audiometric testing in your current job? Yes ( ) No ( )

2.2 Did you undergo any audiometric testing in your former job? Yes ( ) No ( )

Reason for the exam: Professional ( ) Hearing disorder ( )

Did you know about the diagnosis? Yes ( ) No ( ) 


\section{FORMER MORBIDITIES}

Meningitis: Yes ( ) No ( )

Chemotherapy: Yes ( ) No ( )

Renal Failure: Yes ( ) No ( )

Hypothyroidism: Yes ( ) No ( )

Family history of deafness: Yes ( ) No ( )

High blood pressure: Yes ( ) No ( )

Diabetes: Yes ( ) No ( )

Heart Condition: Yes ( ) No ( )

High Cholesterol: Yes ( ) No ( )

Head trauma: Yes ( ) No ( ) Don’t know ()

\section{PERSONAL HISTORY}

4.1 Do you undergo any health treatment? yes ( ) no ( )

Which one?

How long for?

4.2 Do you take any medication? Yes ( ) No ()

Which one? How long for?

4.3 Do you drink any alcoholic drinks: Yes ( ) No ( ) sometimes ( )

How many glasses?

4.4 Do you smoke? Yes ( ) No ( ) sometimes ( )

How many cigarettes a day?

\section{AUDITORY SYMPTOMS}

5.1 Earache (otalgia): Yes ( ) No ( )

Which ear? Right ear ( ) Left ear ( ) Bilateral ( )

5.2 Presence of ear secretion (otorrhea): Yes ( ) No ( )

Which ear? Right ear ( ) Left ear ( ) Bilateral ( )

5.3 If so, how often are those symptoms?

Daily ( ) Weekly ( ) Every fortnight ( )

Hardly ever ( ) Don't know ( )

5.4 Dizziness: Yes ( ) No ()

5.5 Tinnitus: Yes ( ) No ( )

Which ear? Right ear ( ) Left ear ( ) Bilateral ( ) Don’t know ( )

5.6 Frequency of the tinnitus: Daily ( ) Weekly ( )

Every fortnight ( ) Monthly ( ) Hardly ever ( ) Don't know ( )

5.7 What period is tinnitus more intense: After work ( ) All day ( )

Morning ( ) Afternoon ( ) Evening or Night ( ) Don’t know ( )

5.8 Ear surgery: Yes ( ) No ( )

Which ear? Left ear ( ) Right ear ( ) Bilateral ( )

5.9 Hearing trauma: Yes ( ) No ( ) Don't know ( )

5.10 Difficulty in speech understanding: Yes () No () Sometimes ()

In which situation?

\section{NON-AUDITORY SYMPTOMS}

6.1 Irritability: Yes ( ) No ( ) Sometimes ( )

6.2 Tiredness: Yes ( ) No ( ) Sometimes ( )

6.3 Difficulty in concentrating: Yes ( ) No ( ) Sometimes ( )

6.4vBalance disorders: Yes ( ) No ( ) Sometimes ( )

6.5 Sea Sickness: Yes ( ) No ( ) Sometimes ( )

6.6 Vomiting: Yes ( ) No ( ) Sometimes ( )

6.7 Stomachache: Yes ( ) No ( ) Sometimes ( )

6.8 Depression: Yes () No ( ) Sometimes ( )

6.9 Stress: Yes ( ) No ( ) Sometimes ( )

6.10 Headache: Yes () No ( ) Sometimes ( ) 